\title{
Consumer Perception towards High-quality Red Wine in China
}

\author{
Yukun $\mathrm{LI}^{1}$, Feng TAN ${ }^{1}$, Keith WALLEY ${ }^{2}$, Yang XU ${ }^{1}$ * \\ ${ }^{1}$ International College \\ ${ }^{2}$ Food Science and Agri-Food Supply Chain \\ Management Department \\ Harper Adams University \\ Beijing, China \\ *Corresponding author \\ Newport Shropshire, United Kingdom
}

\begin{abstract}
Chinese consumers have their own choice criteria for high-quality red wine. It is found that food quality, brand, packaging, valuable concern and price impact buying aims. Furthermore, consumer characteristic can affect buying high-quality red wine. It is interestingly proved that the higher the education level is, the less effect the aim of buying has.
\end{abstract}

Keywords- high quality; red wine; consumer attitude;

\section{INTRODUCTION}

Wine is defined that it is fermented alcohol drinks which use fresh grapes or grape juice as raw material[1]. There are many classification of the wine. According to the color of finished product, it can be divided into three categories: red wine, white wine and pink wine[2].With the improvement of living standards, more and more people are fond of high-quality red wine (HRW). Due to long history and mature production system of HRW, raw materials and vineyard planting, production brewing technology are superior to that of common wines' companies[3]. At the moment, both Chinese brands and foreign brands compete in Chinese high-quality wine market[4]. In this market, consumers' wine appreciation is generally low. Although consumers have purchasing power, they lack of basic wine knowledge resulting in some product pricing high and manufacturing poor[5].

\section{A. The feature of $H R W$}

High quality red wine uses premium grape as raw materials which are from the special grape planting area, the manufacturers of high quality wine utilize suitable latitude and climate to locate the vineyard. A very strict management and maintenance procedures are adopted in the planting. It has a high requirement in yield, tree age and variety for the vine[6]. Although selecting grapes makes great contribution for good wine, brewing technique in production is also critical, HRW needs special aged oak barrel for cellaring. Furthermore, time, temperature, illumination and brewing technology also have a profound influence on the quality of wine[7].

\section{B. Development of HRW in china}

The Chinese wine consumption is much lower than the average level of the whole world[8], that means development space of wine consumption is very large in China. For example, the world average level of the wine consumption (per capita) is 3.34 liters in 2009, while the level of china is just 0.84 liters, which only account for $25.1 \%$ of the world level[9]. With the further development of the Chinese economy, China will continue a fast rise in number of rich families, and it is predicted more than 4.4 million households in 2015, the numbers ranked fourth and followed the United States[5]. These wealth family will further promote huge demand 
of HRW consumption in China[10].

\section{METHODOLOGY}

In order to explore the factors affecting on HRW sales in Chinese market, 350 questionnaires are distributed to Beijing different districts and 297 are valid. Statistic, cross tabulation and chi-square test are examined in the SPSS software for data analysis.

\section{RESULTS ANALYSIS}

\section{A. Consumer Perception of HRW}

In order to explore the customer preference on HRW, the characteristics of HRW are designed to find out the clients' definition of HRW. It can be seen from Fig. 1: the most concerned characteristic is angiocarpy diseases preventive which accounts for $78 \%$ in all responders. The lowest concerned is enjoyable delicious which is only three tenth of the diseases preventive. That is to say Chinese consumers consider the HRW as healthy food which can prevent diseases and most of them do not accept enjoyably delicious which indicates wine appreciation culture has not formed and wine knowledge are not yet common in China. A previous paper was also stated that Chinese consumers are lack of appreciation ability for wine quality[5].

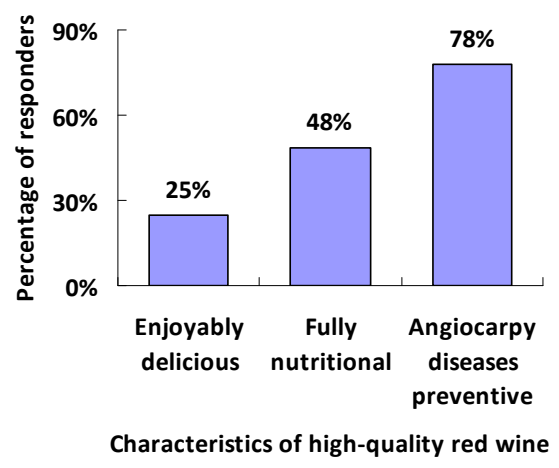

Figure1 Consumer awareness on HRW

\section{B. Objectives of Buying HRW}

It can be seen from the Fig. 2 that the objectives of buying HRW are presented to explore the consumer's perception on product position. 65\% responders believe that HRW is a healthy drink. While communication medium is in the second place(55\%), which is five sixth of healthy drink option. 31\% responder regards it as luxury and communication medium which is only a half percentage of healthy drink. That means Chinese consumers believe the healthy function of HRW is more important than social communication and luxury function. The reason behind the data could be that wine culture is not accompanied to increase by the growth and development of Chinese history and civilization, nor did combine with China's social and cultural life.

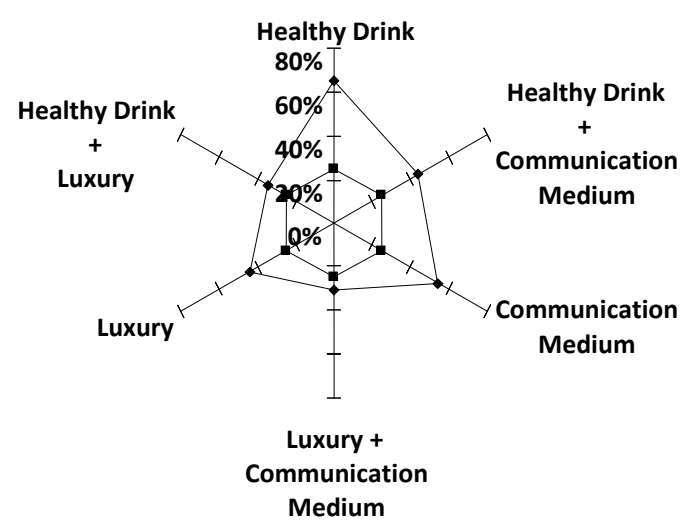

Fig.2: Objectives of buying HRW

\section{C.Buying purposes determine consumer expectations to HRW}

In order to explore the consumer expectations to HRW, cross tabulation and Chi-square test for relationship between buying purpose and factor concerns with buying HRW are implemented in the SPSS software. According to table 1, 47\% consumer concerns the food quality of HRW when aiming for self-consumption, which means they most focus on the food quality when buying HRW for themselves. 34\% client pays attention to brand which indicates brand is most important when purchasing presents. While for collection purpose, packaging concern (33\%) and brand concern (33\%) are both the most important factors. The Chi-square test indicates that the aim of buying HRW can significantly affect the factor concerns with buying HRW. 
Table 1: Cross tabulation and Chi-square test for buying purposes and consumer expectations to HRW

\begin{tabular}{|c|c|c|c|c|c|}
\hline & & Aim of buying $\mathrm{HR}$ & & & \\
\hline & & Self-consumption & Present & Collection & Total \\
\hline & Count in food quality concern & 47 & 40 & 7 & 94 \\
\hline ก & $\%$ within food quality concern & $50 \%$ & $43 \%$ & $7 \%$ & $100 \%$ \\
\hline$\tilde{\tilde{\sigma}}$ & $\%$ within aim of buying & $47 \%$ & $29 \%$ & $13 \%$ & $32 \%$ \\
\hline 3 & $\%$ of Total & $16 \%$ & $14 \%$ & $2 \%$ & $32 \%$ \\
\hline 음 & Count in packaging concern & 12 & 38 & 18 & 68 \\
\hline $\mathscr{B}$ & $\%$ within packaging concern & $18 \%$ & $56 \%$ & $26 \%$ & $100 \%$ \\
\hline E & $\%$ within aim of buying & $12 \%$ & $27 \%$ & $33 \%$ & $23 \%$ \\
\hline$\sum$. & $\%$ of Total & $4 \%$ & $13 \%$ & $6 \%$ & $23 \%$ \\
\hline$\Xi$ & Count in Brand concern & 26 & 47 & 18 & 91 \\
\hline$\Xi$ & \% within Brand concern & $29 \%$ & $52 \%$ & $20 \%$ & $100 \%$ \\
\hline$\exists$ & \% within aim of buying & $26 \%$ & $34 \%$ & $33 \%$ & $31 \%$ \\
\hline$\stackrel{\sigma a}{I+}$ & $\%$ of Total & $9 \%$ & $16 \%$ & $6 \%$ & $31 \%$ \\
\hline$\overline{0}$ & Count valuable concern & 15 & 15 & 12 & 42 \\
\hline & \% within valuable concern & $36 \%$ & $36 \%$ & $29 \%$ & $100 \%$ \\
\hline & \% within aim of buying & $15 \%$ & $11 \%$ & $22 \%$ & $14 \%$ \\
\hline & $\%$ of Total & $5 \%$ & $5 \%$ & $4 \%$ & $14 \%$ \\
\hline & Count & 100 & 140 & 55 & 295 \\
\hline 욤 & $\%$ within all concerns & $34 \%$ & $47 \%$ & $19 \%$ & $100 \%$ \\
\hline$\Xi$ & $\%$ within all aims & $100 \%$ & $100 \%$ & $100 \%$ & $100 \%$ \\
\hline & $\%$ of Total & $34 \%$ & $47 \%$ & $19 \%$ & $100 \%$ \\
\hline Ch & re Tests & Value & df & Asymp. Si & ed) \\
\hline $\mathrm{Pec}$ & Shi-Square & $27.179^{a}$ & 6 & 0.000 & \\
\hline Lik & d Ratio & 28.805 & 6 & 0.000 & \\
\hline Lin & -Linear Association & 8.828 & 1 & 0.003 & \\
\hline $\mathrm{N}$ & d Cases & 295 & & & \\
\hline
\end{tabular}

Except from the above factors, price is also an important factor on purchasing HRW. Price $\mathrm{RMB})$ are divided into three extents: low price (< 700 Yuan), medium price (700-1300 Yuan) and high price ( $>1300$ Yuan) in the survey. It can be seen from table 2 that most consumer (63\%) prefer low price for self-consumption, medium price are the most selected option (46\%) among the present-aim clients and high price is the most selected one (56\%) among the collection-aim customers. The Chi-square test indicates that the aim of buying HRW has significant influence on the expectations to HRW price.

Table 2: Cross tabulation and Chi-square test for buying purposes and expectations to HRW price

\begin{tabular}{|c|c|c|c|c|c|}
\hline & & \multicolumn{4}{|c|}{ Aim of buying high-quality red wine } \\
\hline & & Self-consumption & Present & Collection & Total \\
\hline \multirow{12}{*}{ 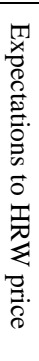 } & Count in low price & 62 & 58 & 6 & 126 \\
\hline & \% within low price & $49 \%$ & $46 \%$ & $5 \%$ & $100 \%$ \\
\hline & $\%$ within aim of buying & $63 \%$ & $41 \%$ & $11 \%$ & $43 \%$ \\
\hline & $\%$ of Total & $21 \%$ & $20 \%$ & $2 \%$ & $43 \%$ \\
\hline & Count in medium price & 25 & 65 & 18 & 108 \\
\hline & $\%$ within medium price & $23 \%$ & $60 \%$ & $17 \%$ & $100 \%$ \\
\hline & $\%$ within aim of buying & $25 \%$ & $46 \%$ & $33 \%$ & $37 \%$ \\
\hline & $\%$ of Total & $9 \%$ & $22 \%$ & $6 \%$ & $37 \%$ \\
\hline & Count high price & 12 & 17 & 31 & 60 \\
\hline & $\%$ within medium price & $20 \%$ & $28 \%$ & $52 \%$ & $100 \%$ \\
\hline & \% within aim of buying & $12 \%$ & $12 \%$ & $56 \%$ & $20 \%$ \\
\hline & $\%$ of Total & $4 \%$ & $6 \%$ & $11 \%$ & $20 \%$ \\
\hline \multirow{4}{*}{$\begin{array}{l}\vec{\circ} \\
\stackrel{0}{ \pm}\end{array}$} & Count & 99 & 140 & 55 & 294 \\
\hline & $\%$ within all prices & $34 \%$ & $48 \%$ & $19 \%$ & $100 \%$ \\
\hline & \% within all aims & $100 \%$ & $100 \%$ & $100 \%$ & $100 \%$ \\
\hline & $\%$ of Total & $34 \%$ & $48 \%$ & $19 \%$ & $100 \%$ \\
\hline \multicolumn{2}{|c|}{ Chi-Square tests } & Value & df & \multicolumn{2}{|c|}{ Asymp. Sig. (2-sided) } \\
\hline \multicolumn{2}{|c|}{ Pearson Chi-Square } & $72.427^{\mathrm{a}}$ & 4 & 0.000 & \\
\hline \multicolumn{2}{|c|}{ Likelihood Ratio } & 67.059 & 4 & 0.000 & \\
\hline \multicolumn{2}{|c|}{ Linear-by-Linear Association } & 49.241 & 1 & 0.000 & \\
\hline \multicolumn{2}{|c|}{$\mathrm{N}$ of Valid Cases } & 294 & & & \\
\hline
\end{tabular}

\section{Consumer characteristics impact on buying $H R W$}

Consumer characteristics that impact on buying HRW are also explored from four aspects: Income, Knowledge about red wine, Age and
Education. Correlation Test examined four aspects with aim of buying, willing to buy and acceptable price respectively in the table 3 . Firstly, it can be observed that income can significantly affect the aim of buying, willing to 
buy and price acceptable. That is to say high-income group have the demand to buy the HRW and can afford the price of HRW. Furthermore, they have aims to buy the HRW, such as self-consumption, present and collection. Secondly, knowledge about red wine has a significant influence on the willing to buy and price acceptable, which means the client who has the wine knowledge, prefer to buy the HRW and to accept the price of HRW. The reason could be that consumers who have the wine knowledge are capable to appreciate wine quality and realize the value of the wine. Thirdly, there is a significant correlation between age and aim of buying with willing to buy, which indicates that with the increase of age, the consumers have different aims and are more willing to buy the HRW. However, to be interesting noticed there is a negative relationship between education and aim of buying

Table 3: Bivariate correlation test between consumer characteristics and purchase factors.

\begin{tabular}{lllll}
\hline & & Aim of buying & Willing to buy & Price acceptable \\
\hline Income & Pearson Correlation & $0.194^{* *}$ & $0.270^{* *}$ & $0.268^{* *}$ \\
& Sig. (2-tailed) & 0.003 & 0.000 & 0.000 \\
& $\mathrm{~N}$ & 293 & 293 & 293 \\
\hline Knowledge about & Pearson Correlation & 0.081 & $0.554^{* *}$ & $0.217^{* *}$ \\
Red wine & Sig. (2-tailed) & 0.166 & 0.000 & 0.000 \\
& $\mathrm{~N}$ & 293 & 294 & 293 \\
\hline Age & Pearson Correlation & $0.139^{*}$ & $0.129^{*}$ & 0.086 \\
& Sig. (2-tailed) & 0.017 & 0.027 & 0.143 \\
& $\mathrm{~N}$ & 294 & 294 & 294 \\
\hline Education & Pearson Correlation & $-0.119^{*}$ & 0.053 & 0.002 \\
& Sig. (2-tailed) & 0.042 & 0.366 & 0.971 \\
& $\mathrm{~N}$ & 293 & 293 & 293 \\
\hline
\end{tabular}

\section{CONCLUSION}

Most Chinese consumers regard HRW as healthy food and they do not consider it as luxury and communication medium, as appreciation culture and wine knowledge are not common in China. And buying purposes can significantly affect consumer expectations to HRW and expectation price. In addition, consumer characteristics (Income, Knowledge about red wine, Age and Education.) can affect the buying HRW.

\section{ACKNOWLEDGMENT}

Beijing University of Agriculture and the research centre funded by Harper Adams University UK gave support to the article. It was appreciated that a group of undergraduate student, Ruyue Song et al, involved in the primary works.

\section{REFERENCES}

[1] S. Jin-xiao, L. Jie, Z. Yan, and Y. Ya-qing, "Wine Appreciation and Storage," Journal of Researches on Dietetic Science and Culture, vol. 32, pp. 55-58, 2015.

[2] L. Yang, Z. an, Z. Zhizhuang, and Z. Yonghe, "The Property and Subject Classification of Sino-Overseas Grapevine \& Wine," Journal of Anhui Agricultural Sciences, vol. 40, p. 3, 2012.

[3] W. Pingping, "Red wine development gap between China and abroad," Journal of Huaibei Professional and Technical College, vol. 12, pp. 102-104, 2014.

[4] L. Feng, "Chinese wine market status and trends," Market Weekly, vol. 10, pp. 30-33, 2012.

[5] L. Jiagui. (2014, 27th May). consumer behavior research for Chiese wine. Available: http://www.cnki.net/kcms/detail/detailall.aspx?fil ename $=1014430854$.nh\&dbcode=CDFD\&dbnam $\mathrm{e}=$ CDFD2015

[6] G. Nianfa, Wine production techniques. Beijing: Chemical Industry Press, 2005.

[7] Z. Yang and Z. Jiyi, "Discussion on the Quality of Chinese Grape Wine and its development," Liquor-making Science and Technology, vol. 2011, pp. 132-134, 2011.

[8] Z. Lei, "The next golden decade for wine industry---from the perspective of resources, brand, channels," China Jianyin Investment Securities, Shen Zhen2011.

[9] Anderson K and N. S, Global wine markets, 1961 to 2009: a statistical compendium. Adelaide:: The University of Adelaide Press, 2011.

[10] M. O. Reports. (2013, 27th May). Wine - China November 2013.2 Available: http://academic.mintel.com.hau.idm.oclc.org/disp lay/642937/ 